\title{
RESEARCH
}

Open Access

\section{Lymphopenia in severe coronavirus disease-2019 (COVID-19): systematic review and meta-analysis}

\author{
lan Huang ${ }^{1,2}$ (B) and Raymond Pranata ${ }^{1 *}$ (D)
}

\begin{abstract}
Objective: Clinical and laboratory biomarkers to predict the severity of coronavirus disease 2019 (COVID-19) are essential in this pandemic situation of which resource allocation must be urgently prepared especially in the context of respiratory support readiness. Lymphocyte count has been a marker of interest since the first COVID-19 publication. We conducted a systematic review and meta-analysis in order to investigate the association of lymphocyte count on admission and the severity of COVID-19. We would also like to analyze whether patient characteristics such as age and comorbidities affect the relationship between lymphocyte count and COVID-19.

Methods: Comprehensive and systematic literature search was performed from PubMed, SCOPUS, EuropePMC, ProQuest, Cochrane Central Databases, and Google Scholar. Research articles in adult patients diagnosed with COVID-19 with information on lymphocyte count and several outcomes of interest, including mortality, acute respiratory distress syndrome (ARDS), intensive care unit (ICU) care, and severe COVID-19, were included in the analysis. Inverse variance method was used to obtain mean differences and its standard deviations. MaentelHaenszel formula was used to calculate dichotomous variables to obtain odds ratios (ORs) along with its 95\% confidence intervals. Random-effect models were used for meta-analysis regardless of heterogeneity. Restrictedmaximum likelihood random-effects meta-regression was performed for age, gender, cardiac comorbidity, hypertension, diabetes mellitus, COPD, and smoking.
\end{abstract}

Results: There were a total of 3099 patients from 24 studies. Meta-analysis showed that patients with poor outcome have a lower lymphocyte count (mean difference - 361.06 $\mu \mathrm{L}[-439.18,-282.95], p<0.001$; $\left.\right|^{2} 84 \%$ ) compared to those with good outcome. Subgroup analysis showed lower lymphocyte count in patients who died (mean difference $-395.35 \mu \mathrm{L}[-165.64,-625.07], p<0.001 ; P^{2} 87 \%$ ), experienced ARDS (mean difference $377.56 \mu \mathrm{L}[-271.89,-483.22], p<0.001 ; P^{2} 0 \%$ ), received ICU care (mean difference $-376.53 \mu \mathrm{L}[-682.84,-70.22]$, $\left.p=0.02 ; P^{2} 89 \%\right)$, and have severe COVID-19 (mean difference $-353.34 \mu \mathrm{L}[-250.94,-455.73], p<0.001 ; P^{2} 85 \%$ ). Lymphopenia was associated with severe COVID-19 (OR $\left.3.70[2.44,5.63], p<0.001 ; P^{2} 40 \%\right)$. Meta-regression showed that the association between lymphocyte count and composite poor outcome was affected by age $(p=0.034)$.

Conclusion: This meta-analysis showed that lymphopenia on admission was associated with poor outcome in patients with COVID-19.

Keywords: Coronavirus, COVID-19, Lymphocyte count, Lymphopenia, SARS-CoV-2

\footnotetext{
* Correspondence: raymond_pranata@hotmail.com

${ }^{1}$ Faculty of Medicine, Universitas Pelita Harapan, Tangerang, Banten, Indonesia

Full list of author information is available at the end of the article
}

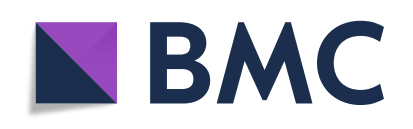

(- The Author(s). 2020 Open Access This article is licensed under a Creative Commons Attribution 4.0 International License, which permits use, sharing, adaptation, distribution and reproduction in any medium or format, as long as you give appropriate credit to the original author(s) and the source, provide a link to the Creative Commons licence, and indicate if changes were made. The images or other third party material in this article are included in the article's Creative Commons licence, unless indicated otherwise in a credit line to the material. If material is not included in the article's Creative Commons licence and your intended use is not permitted by statutory regulation or exceeds the permitted use, you will need to obtain permission directly from the copyright holder. To view a copy of this licence, visit http://creativecommons.org/licenses/by/4.0/. The Creative Commons Public Domain Dedication waiver (http://creativecommons.org/publicdomain/zero/1.0/) applies to the data made available in this article, unless otherwise stated in a credit line to the data. 


\section{Introduction}

Coronavirus disease 2019 (COVID-19) has been declared by the World Health Organization (WHO) as a global public health emergency due to its pandemicity [1]. Since its first emergence in Wuhan, China, more than 450,000 cases and 20,000 deaths have been recorded globally due to COVID-19 [2]. While most patients with COVID-19 have mild influenza-like illness and may be asymptomatic, a minority of patients will develop severe pneumonia, acute respiratory distress syndrome (ARDS), multi-organ failure (MOF), and death [3]. Clinical and laboratory biomarkers [4] to predict the mortality and severity of COVID-19 are essential in this pandemic situation of which resource allocation must be urgently prepared especially in the context of respiratory support readiness.

Since the first descriptive study in China regarding the COVID-19 infection [5], lymphocyte count has been a marker of interest. It has been associated with severe COVID-19 [6, 7], and non-survivors of COVID-19 were reported to have a significantly lower lymphocyte count than survivors [7]. Whether lower lymphocyte count and lymphopenia could really be predictor of severity of COVID-19 was our main interest, since this laboratory tools are readily available even in the remote areas. Therefore, in the present study, we conducted a systematic review and meta-analysis in order to investigate the association of lymphocyte count on admission and the severity of COVID-19. We would also like to analyze whether patient characteristics such as age and comorbidities affect the relationship between lymphocyte count and COVID-19.

\section{Material and methods Eligibility criteria}

We included research articles concerning adult patients diagnosed with COVID-19 that has information on lymphocyte count at admission, and clinical grouping or outcome of clinically validated definition of severe COVID-19, death, or ICU care. We exclude review articles, non-research letters, commentaries, case reports, animal studies, original research with samples below 20 or case reports and series, non-English language articles, and studies in pediatric populations ( $\leq 17$ years old).

\section{Search strategy and study selection}

We systematically searched PubMed, SCOPUS, EuropePMC, ProQuest, Cochrane Central Databases, and Google Scholar with the search terms "COVID-19" OR "SARSCoV-2" AND "Lymphocyte" (Table S1). After initial search, duplicates were excluded. Two independent authors (IH and RP) screened title and abstracts for potentially relevant articles. The full-text of the potential articles was assessed by applying inclusion and exclusion criteria. The literature search was finalized on March 25, 2020. The study was carried out in accordance with the declaration of Helsinki and with the term of local protocol. This is a Preferred Reporting Items for Systematic Reviews and Meta-Analyses (PRISMA)-compliant systematic review and meta-analysis

\section{Data extraction}

Data extraction was performed independently by two authors (IH and RP). We used standardized forms that included author, year, study design, age, gender, cardiac comorbidities, hypertension, diabetes mellitus, chronic obstructive pulmonary disease, smoking, lymphocyte count, lymphopenia, mortality, ARDS, ICU care, and severe COVID-19.

The outcome of interest was composite poor outcome that comprised of mortality, ARDS, ICU care, and severe COVID-19. Mortality and ICU care was defined as death and admittance to ICU during inhospital care, respectively. ARDS was defined according to the criteria from the World Health Organization (WHO) interim guidance for severe acute respiratory infection (SARI) in COVID-19, which includes the acuity of symptom onset, chest X-ray and origin of pulmonary infiltrates, and oxygenation impairment [8]. Severe COVID-19 was defined as patients who had any of the following features at the time of, or after, admission: (1) respiratory rate $\geq 30$ breaths per min, (2) oxygen saturation $\leq 93 \%$ (at rest), (3) ratio of partial pressure of arterial oxygen to fractional concentration of oxygen inspired air ( $\mathrm{PaO} 2$ to fiO2 ratio) $\leq 300 \mathrm{mmHg}$, or (4) specific complications, such as septic shock, respiratory failure, and or multiple organ dysfunction [9].

\section{Statistical analysis}

The meta-analysis of studies was performed using Review Manager 5.3 (Cochrane Collaboration) and Stata version 16. To pool continuous variables, we used an inverse variance method to obtain mean differences (MDs) and its standard deviations (SDs). Maentel-Haenszel formula was used to calculate dichotomous variables to obtain odds ratios (ORs) along with its 95\% confidence intervals (CIs). We used random-effects models for pooled analysis regardless of heterogeneity. All $P$ values were two-tailed, and statistical significance was set at $\leq 0.05$. Subgroup analysis was performed for lymphopenia cutoff point at $\leq 1100$ cells $/ \mu \mathrm{L}$. Sensitivity analysis using a leave-one-out method was performed to single out the cause of heterogeneity. Regression-based Egger's test was used to assess smallstudy effects for continuous variables and Harbord's test for binary outcome. Restricted maximum likelihood randomeffects meta-regression was performed for age, gender, cardiac comorbidity, hypertension, diabetes mellitus, chronic obstructive pulmonary disease (COPD), and smoking.

\section{Results}

Baseline characteristics and study selection

We found a total of 150 records of which 132 remained after the removal of duplicates. A total of 105 records 
were excluded after screening the title/abstracts. After assessing 27 articles for eligibility, we excluded 4 in which lymphocyte count was unavailable. Thereby, 23 studies remained for qualitative synthesis and meta-analysis (Fig. 1). There were a total of 3099 patients from 23 studies [57, 10-29]. Baseline characteristics are presented in Table 1 . The reported mean age of the patients on these studies was 51 years old; $55 \%$ of the overall samples were men. Most studies reported lymphocyte count on admission except for Ruan et al. and Liu et al. whom did not state the period of blood test. Nevertheless, their study presumably reported lymphocyte counts on admission.

\section{Lymphocyte count and poor outcome}

Meta-analysis showed that patients with poor outcome had a lower lymphocyte count (mean difference - 361.06 $\mathrm{LL}$ [- 439.18, - 282.95], $p<0.001 ; I^{2} 84 \%, p<$ 0.001) compared to those with good outcome (Fig. 2a). Subgroup analysis showed that patients that died had lower lymphocyte count (mean difference $-395.35 \mu \mathrm{L}[-$ 165.64, - 625.07], $p<0.001 ; I^{2}$ 87\%, $\left.p<0.001\right)$. Patients with ARDS had lower lymphocyte count (mean difference - 377.56 $\mu \mathrm{L}[-271.89,-483.22], p<0.001 ; I^{2} 0 \%, p=$ $0.35)$. Patients in ICU care had lower lymphocyte count (mean difference $-376.53 \mu \mathrm{L}[-682.84,-70.22], p=0.02$; $\left.I^{2} 89 \%, p<0.001\right)$. Patients with severe COVID-19 had lower lymphocyte count compared to non-severe COVID19 patients (mean difference - 353.34 $\mu \mathrm{L}[-250.94$, - 455.73], $p<0.001 ; I^{2} 85 \%, p<0.001$ ) (Table 2).

Sensitivity analysis showed that removal of one particular study [24] reduced the heterogeneity for ICU outcome, but lymphocyte count was still lower in those that received ICU care (mean difference - $503.51 \mu \mathrm{L}$ [- 638.11, 368.92], $\left.p<0.001 ; I^{2} 0 \%, p=0.41\right)$. Removal of any single study did not significantly reduce heterogeneity for mortality, ARDS, and severe COVID-19.

\section{Lymphopenia and severe COVID-19}

Meta-analysis showed that lymphopenia was associated with severe COVID-19 (OR 3.70 [2.44, 5.63], $p<0.001$; $I^{2} 40 \%, p=0.14$ ) (Fig. 2b). Subgroup analysis was performed for lymphopenia with definition of lymphocyte
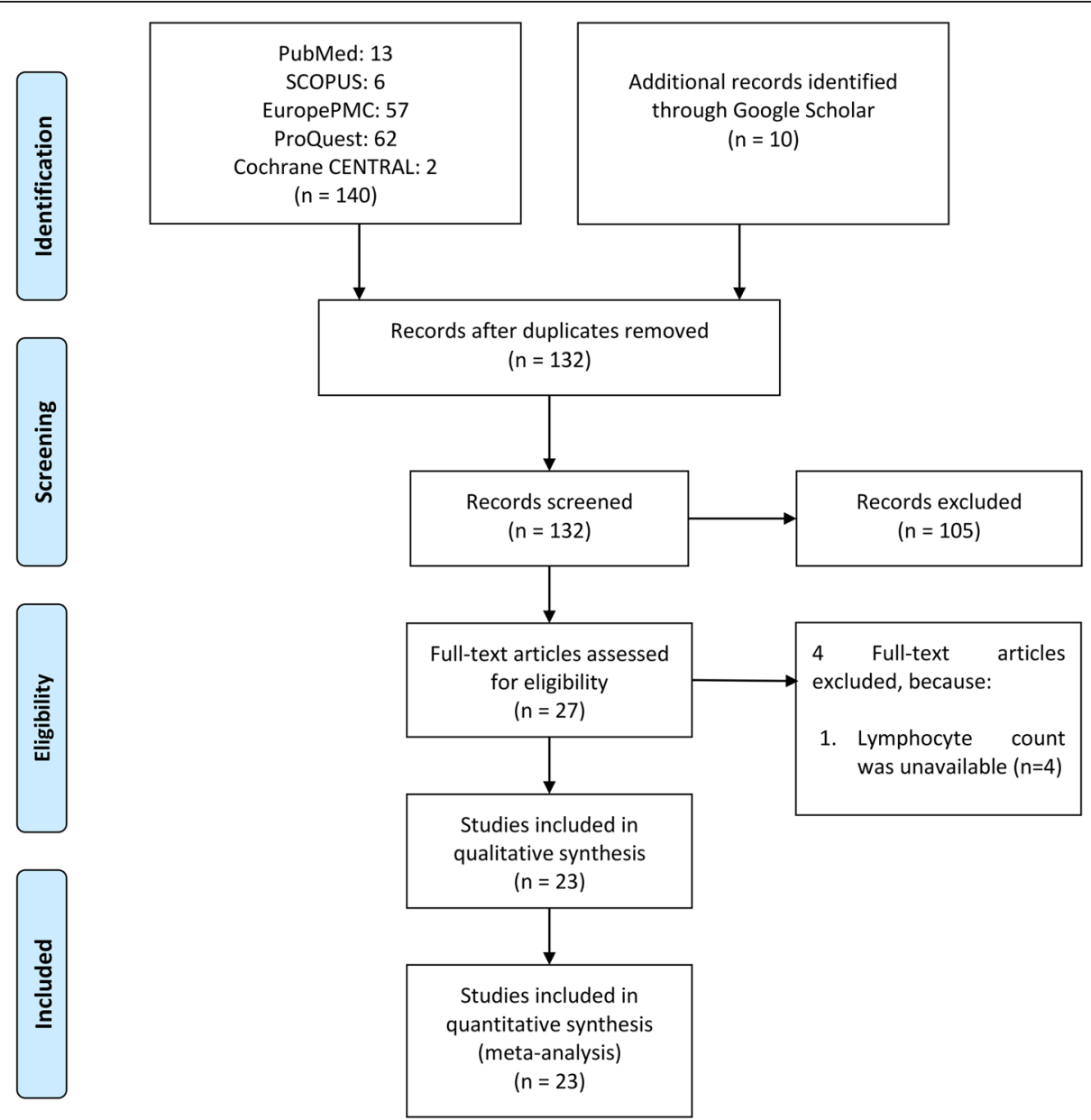

Fig. 1 Study flow diagram 
Table 1 Baseline characteristics of the included studies

\begin{tabular}{|c|c|c|c|c|c|c|c|c|}
\hline Author & Study design & Country & $\begin{array}{l}\text { Sample } \\
\text { (n) }\end{array}$ & $\begin{array}{l}\text { Gender } \\
\text { (male \%) }\end{array}$ & Age (years) & $\begin{array}{l}\text { Cardiac } \\
\text { comorbidity (\%) }\end{array}$ & HT (\%) & DM (\%) \\
\hline Ruan et al. 2020 [7] & Retrospective & Wuhan, China & 150 & $102 / 150(68 \%)$ & $\begin{array}{l}67 \text { non-survivor and } \\
50 \text { survivor (median) }\end{array}$ & 8.7 & 34.7 & 16.7 \\
\hline Yang et al. 2020 [6] & Retrospective & Wuhan, China & 52 & $35 / 52(67 \%)$ & 59.7 (mean) & 9.6 & NR & 17.3 \\
\hline Zhou et al. 2020 [20] & Retrospective & Wuhan, China & 191 & 119/191 (62\%) & 56 (median) & 7.9 & 30.4 & 18.8 \\
\hline Chen et al. 2020 [23] & Retrospective & Wuhan, China & 124 & $61 / 124(49 \%)$ & $\begin{array}{l}72 \text { non-survivor and } \\
53 \text { survivor (median) }\end{array}$ & 16.1 & 33.1 & 11.3 \\
\hline Huang et al. 2020 [5] & Retrospective & Wuhan, China & 41 & 30/41 (73\%) & 49 (median) & 14.6 & 14.6 & 19.5 \\
\hline Wang et al. 2020 [24] & Retrospective & Wuhan, China & 138 & 75/138 (54\%) & 56 (median) & 14.5 & 31.2 & 10.1 \\
\hline Cao et al. 2020 [25] & Retrospective & Shanghai, China & 198 & 101/198 (51\%) & 50.1 (mean) & 6.1 & 21.2 & 7.6 \\
\hline Wu et al. 2020 [26] & Retrospective & Wuhan, China & 201 & 30/41 (73\%) & 51 (median) & 4.0 & 19.4 & 10.9 \\
\hline Yanli et al. 2020 [27] & Retrospective & Wuhan, China & 109 & $59 / 109$ (54\%) & 55 (median) & 6.4 & 33.9 & 11.0 \\
\hline Guan et al. 2020 [28] & Retrospective & Wuhan, China & 1099 & 640/1099 (58\%) & 47 (median) & 2.5 & 15.0 & 7.4 \\
\hline Liu et al. 2020 [29] & Retrospective & Wuhan, China & 78 & $39(58 \%)$ & 38 (median) & NR & 10.3 & 6.4 \\
\hline Zhang G et al 2020 [10] & Retrospective & Wuhan, China & 221 & 108/221 (48.9\%) & 55 (median) & 10.0 & 24.4 & 10.0 \\
\hline Zhang et al. 2020 [11] & Retrospective & Wuhan, China & 140 & $71 / 140(50.7 \%)$ & 57 (median) & 5.0 & 30.0 & 12.1 \\
\hline Wan et al. 2020 [12] & Retrospective & Chongqing, China & 135 & $72 / 135(53.3 \%)$ & 47 (median) & 5.0 & 9.6 & 8.9 \\
\hline Qu et al. 2020 [13] & Retrospective & Huizhoi, China & 30 & $16 / 30(53.3 \%)$ & 50.5 (median) & NR & NR & NR \\
\hline Qin et al. 2020 [14] & Retrospective & Wuhan, China & 452 & $235 / 452(52 \%)$ & 58 (median) & 6.0 & 29.9 & 16.6 \\
\hline Wang et al. 2020 [15] & Retrospective & Wuhan, China & 110 & 48/110 (43\%) & $\begin{array}{l}\leq 40(53 \%), 41-60 \\
(21 \%),>60(36 \%)\end{array}$ & 6.4 & 20.9 & 13.6 \\
\hline Feng et al. 2020 [16] & Retrospective & Wuhan, China & 141 & $72 / 141(51.1 \%)$ & 44 (median) & 2.7 & 14.9 & 5.7 \\
\hline Lei et al. 2020 [17] & Retrospective & Chongqing, China & 51 & $32 / 51(62.7 \%)$ & 45 (median) & $N R$ & 7.8 & 7.8 \\
\hline Liu et al. 2020 [18] & Retrospective & Wuhan, China & 40 & $15 / 40(37.5 \%)$ & 48.7 (mean) & $N R$ & 15.0 & 15.0 \\
\hline Cai et al. 2020 [19] & Retrospective & Shenzhen, China & 298 & 149/298 (50\%) & 47 (median) & $N R$ & NR & NR \\
\hline Liu et al. 2020 [21] & Prospective & Beijing, China & 61 & 31/61 (50.8) & 40 (median) & 1.6 & 19.7 & 8.2 \\
\hline Tabata et al. 2020 [22] & Retrospective & Tokyo, Japan & 104 & 47/104 (45\%) & 68 (median) & NR & $N R$ & NR \\
\hline
\end{tabular}

$N R$ not reported, $D M$ diabetes mellitus, $H T$ hypertension

count $\leq 1100 \mu \mathrm{L}$, showing that lymphopenia was associated with severe COVID-19 (OR 3.27 [1.85, 5.78], $p<$ $0.001 ; I^{2} 55 \%, p=0.08$ ) (Figure S1).

\section{Meta-regression}

Random-effects meta-regression analysis showed that the association between lower lymphocyte count in patients with composite poor outcome was affected by age $(p=0.034)$ (Fig. 3a), but not by gender $(p=0.109)$, cardiac comorbidity ( $p=0.953)$ (Fig. $3 \mathrm{~b})$, hypertension $(p=$ $0.065)$ (Fig. 3c), diabetes mellitus $(p=0.931)$, COPD ( $p$ $=0.798)$, and smoking $(p=0.581)$.

\section{Subgroup analysis for age}

Since the composite poor outcome was affected by age, we performed subgroup analysis by using 55 years old as cutoff point. The difference in lymphocyte count in $<55$ years old (mean difference $-378.93 \mu \mathrm{L}$ $\left.[-472.58,-285.27], p<0.001 ; I^{2} 81 \%, p<0.001\right)$ was greater compared to those in $\geq 55$ years old (mean difference - 341.68 $\mu \mathrm{L}[-484.25,-199.11], p<0.001 ; I^{2}$ $87 \%, p<0.001)$. The association between lymphopenia and severe COVID-19 was stronger in $<55$ years old (OR $\left.5.32[3.46,8.18], p<0.001 ; I^{2} 0 \%, p=0.75\right)$ compared to $\geq 55$ years old (OR 2.38 [1.48, 3.84], $p<$ $0.001 ; I^{2} 0 \%, p=0.42$ ).

\section{Publication bias}

Funnel plot analysis showed asymmetrical shape for lymphocyte count and composite poor outcome (Fig. 4). The funnel plot was symmetrical for lymphopenia and severe COVID-19. Regression-based Egger's test showed statistically significant small-study effects $(p=0.018)$ for the lymphocyte and composite poor outcome. Trimand-fill method did not impute any study. Regressionbased Harbord's test showed no evidence of small-study effects $(p=0.086)$ for lymphopenia and severe COVID19 outcome. 


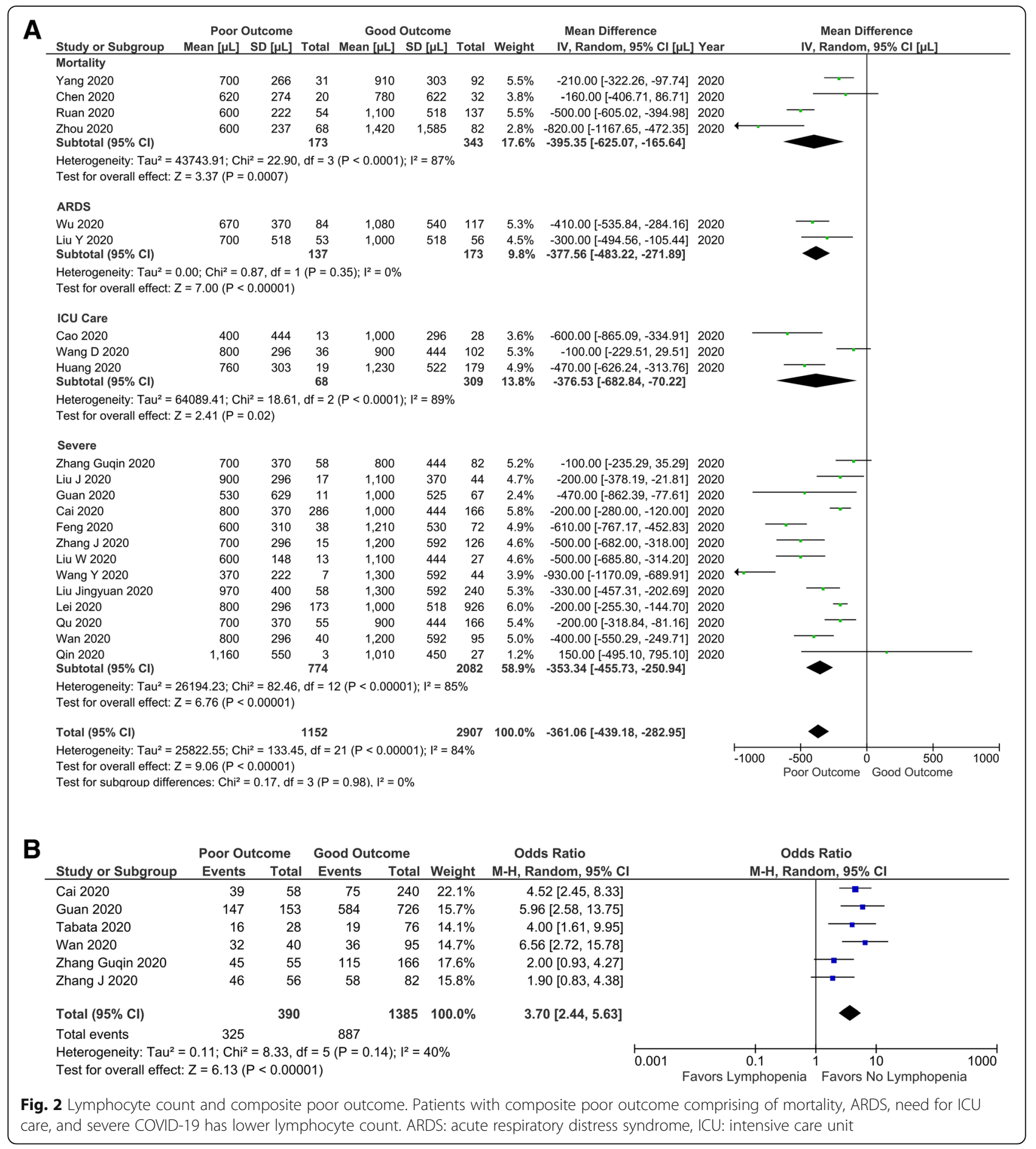

\section{Discussion}

This meta-analysis showed that lower lymphocyte count was associated with increased mortality, ARDS, need for ICU care, and severe COVID-19. The association seemed to be stronger in younger patients compared to older patients.

Although the definition of lymphopenia differed among studies, a subgroup analysis using $\leq 1100$ cells $/ \mu \mathrm{L}$ cut-off point has showed a consistent outcome in four studies [10$12,19]$. We set a cut-off point of $\leq 1100 \mu \mathrm{L}$ because there were 4 studies using it as a cutoff point. There were only 2 studies for $\leq 1000 \mu \mathrm{L}$, and 1 study for $<1200 \mu \mathrm{L}$ and $\leq 1500 \mu \mathrm{L}$, respectively. This subgroup analysis aimed to determine the magnitude of odds ratio at a specific cutoff point (not because of its superiority over the other cutoff points). 
Table 2 Lymphocyte count and outcome of the included studies

\begin{tabular}{|c|c|c|c|c|c|c|c|c|}
\hline Author & $\begin{array}{l}\text { Smoking } \\
(\%)\end{array}$ & $\begin{array}{l}\text { COPD } \\
(\%)\end{array}$ & Poor outcome (\%) & $\begin{array}{l}\text { Lymphocyte } \\
\text { count in good } \\
\text { outcome }(/ \mu \mathrm{L})\end{array}$ & $\begin{array}{l}\text { Lymphocyte } \\
\text { count in poor } \\
\text { outcome }(/ \mu \mathrm{L})\end{array}$ & $\begin{array}{l}\text { Lymphopenia } \\
\text { cutoff }\end{array}$ & $\begin{array}{l}\text { Lymphopenia } \\
\text { in good } \\
\text { outcome (\%) }\end{array}$ & $\begin{array}{l}\text { Lymphopenia } \\
\text { in poor } \\
\text { outcome (\%) }\end{array}$ \\
\hline Ruan et al. 2020 [7] & NR & 2.0 & $68 / 150(45 \%)$, death & $1420(2140)$ & $600(320)$ & NR & NR & NR \\
\hline Yang et al. 2020 [6] & 4 & 7.6 (CLD) & 20/52 (38\%), death & $740(840)$ & $620(370)$ & NR & NR & NR \\
\hline Zhou et al. 2020 [20] & 5.7 & 3.1 & $54 / 191(28 \%)$, death & $1100(800-1500)$ & $600(500-800)$ & NR & $N R$ & NR \\
\hline Chen et al. 2020 [23] & 13.8 & 4.9 & $31 / 123(25 \%)$, death & $910(410)$ & $700(360)$ & NR & NR & NR \\
\hline Huang et al. 2020 [5] & 7.3 & 2.4 & 13/41 (31\%), ICU & $1000(700-1100)$ & $400(200-800)$ & $\leq 1000$ & $15 / 28(54 \%)$ & 11/13 (85\%) \\
\hline Wang et al. 2020 [24] & NR & 2.9 & 36/138 (26\%), ICU & $900(600-1200)$ & 800 (500-900) & NR & NR & NR \\
\hline Cao et al. 2020 [25] & 5.6 & NR & 19/198 (9\%), ICU & $1230(860-1565)$ & 760 (530-940) & $\leq 1000$ & $1 / 179(0.6 \%)$ & 16/19 (84\%) \\
\hline Wu et al. 2020 [26] & NR & 2.5 (CLD) & 84/201 (41\%), ARDS & $1080(720-1450)$ & 670 (490-990) & NR & NR & NR \\
\hline Liu et al. 2020 [27] & NR & 3.7 & 53/109 (48\%), ARDS & $1000(800-1400)$ & 700 (400-1100) & NR & $N R$ & NR \\
\hline Guan et al. 2020 [28] & 14.4 & 1.1 & 173/1099 (15\%), severe & $1000(800-1400)$ & $800(600-1000)$ & $\leq 1500$ & $584 / 726(83.2 \%)$ & 147/153 (96.1\%) \\
\hline Liu et al. 2020 [29] & 6.4 & 10.0 & $11 / 78(14 \%)$, severe & $1000(680-1390)$ & $530(300-1150)$ & NR & $N R$ & NR \\
\hline Zhang et al. 2020 [10] & $N R$ & 2.7 & $55 / 221(24 \%)$, severe & $900(600-1200)$ & $700(400-900)$ & $\leq 1100$ & 115/166 (69\%) & 48/55 (87\%) \\
\hline Zhang et al. 2020 [11] & 6.4 & 1.4 & $58 / 140(34 \%)$, severe & $800(600-1200)$ & $700(500-1000)$ & $\leq 1100$ & $58 / 82(70 . \%)$ & 46/56 (82.1\%) \\
\hline Wan et al. 2020 [12] & 6.7 & 0.7 (CLD) & 40/135 (29\%), severe & $1200(800-1600)$ & $800(600-1000)$ & $\leq 1100$ & 36/95 (38\%) & $32 / 40$ (80\%) \\
\hline Qu et al. 2020 [13] & NR & NR & $3 / 30(10 \%)$, severe & $1010(450)$ & $1160(550)$ & NR & NR & NR \\
\hline Qin et al. 2020 [14] & 1.5 & 2.6 & $286 / 452(63 \%)$, severe & $1000(700-1300)$ & $800(600-1100)$ & NR & $N R$ & NR \\
\hline Wang et al. 2020 [15] & 23.6 & 5.4 & $38 / 110(34 \%)$, severe & $1210(530)$ & $600(310)$ & NR & NR & NR \\
\hline Feng et al. 2020 [16] & 4.9 & 2.8 & $15 / 141(10 \%)$, severe & $1200(800-1600)$ & $700(600-1000)$ & NR & $N R$ & NR \\
\hline Lei et al. 2020 [17] & NR & NR & 7/51 (13\%), severe & $1300(900-1700)$ & $370(300-600)$ & NR & $N R$ & NR \\
\hline Liu et al. 2020 [18] & NR & NR & $13 / 40(32.5 \%)$, severe & $1100(800-1400)$ & $600(600-800)$ & NR & $N R$ & NR \\
\hline Cai et al. 2020 [19] & $N R$ & NR & $58 / 298(19 \%)$, severe & $1300(1000-1800)$ & $970(650-1190)$ & $\leq 1100$ & 75/240 (31.3\%) & 39/58 (67\%) \\
\hline Liu et al. 2020 [21] & 6.6 & 8.2 & $17 / 61(27 \%)$, severe & $1100(900-1400)$ & $900(700-1100)$ & NR & $N R$ & NR \\
\hline Tabata et al. 2020 [22] & 17.3 & 6.7 (CLD) & 28/104 (26\%), severe & NR & NR & $<1200$ & 19/76 (25\%) & 16/28 (57.1\%) \\
\hline
\end{tabular}

Lymphocyte count presented as median (IQR) or mean (SD). Smoking includes current and/or former smoker

$N R$ not reported, CLD chronic lung disease/pulmonary disease

Based on the meta-regression result, subgroup analysis of age group by using 55 years old as the cutoff point was performed. By analyzing the bubble plot chart, the center of bubble plot is approximately 52 to 55 years old. Hence, we chose 55 as the cutoff point to ensure the number of studies is almost equal in the left side and the right side of the bubble plot. If the number of studies was too small, the pooled effect estimate will be less reliable. Interestingly, we found that the association between lymphopenia and severe COVID-19 was stronger in younger patients compared to older patients. This was a novel finding which, as far as we know, has not been discussed in previous literature. Although changes in the number and composition of lymphocytes are considered as hallmark of immunosenescence [30], it could not fully explain this association. One possible hypothesis is that the aging of the immune system could contribute to a relatively "non-reactive" immune state, thereby causing a relatively stable reduced lymphocyte count, while in younger populations, the highly active lymphocyte kinetics may be influenced by a wide range of insults and comorbidities, thus contributing to a relatively higher mean difference between younger populations.
This is further reflected by the sensitivity analysis which showed that upon removal of Wang et al. study, heterogeneity can be reduced to $0 \%$ for the ICU care outcome. This heterogeneity was attributed to the mean/median age; there were 3 studies for the ICU care outcome, Cao et al. (50.1 years old), Wang et al. (56 years old), and Huang et al. (49 years old). The difference between mean/median age of Cao et al. and Huang et al. was only 1.1 years old. This explains why the heterogeneity between Cao et al. and Huang et al. was low (0\%).

Pre-existing cardiac disease has been shown to increase mortality in patients with COVID-19 [20]; in this metaanalysis, cardiac comorbidity was not found to affect the association between lymphocyte count difference and composite poor outcome. Angiotensin-converting enzyme (ACE) inhibitor and angiotensin-receptor blocker (ARB) have been hypothetically suggested to exacerbate COVID19 due to increase in angiotensin II level [31]. These drugs are frequently used in patients with diabetes and hypertension, which was associated with poor outcome [32, 33]. Although we did not have data on hypertensive medications in the present study, meta-regression showed that 


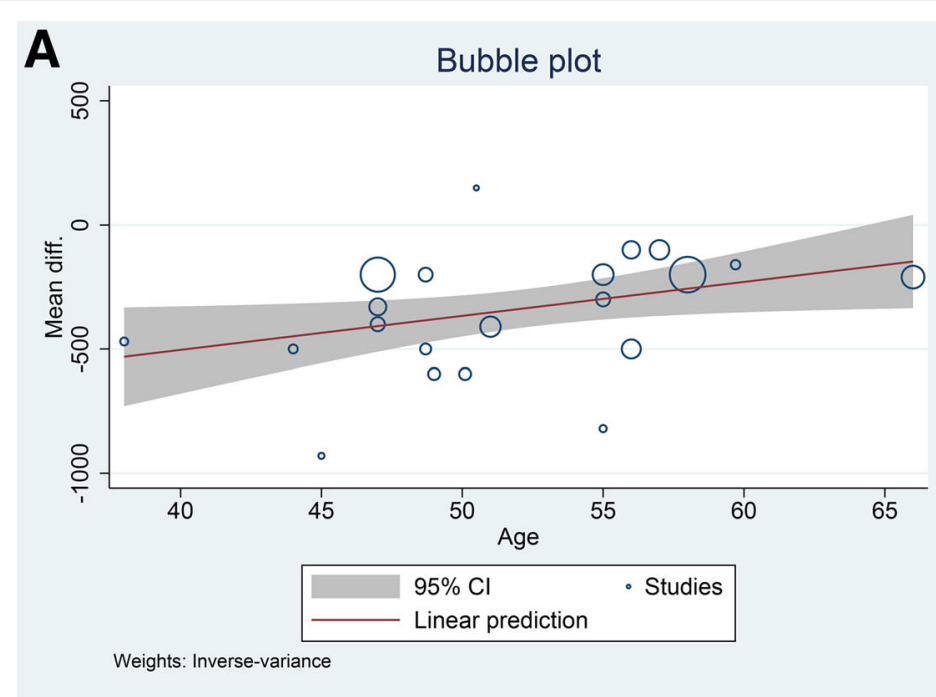

B

Bubble plot
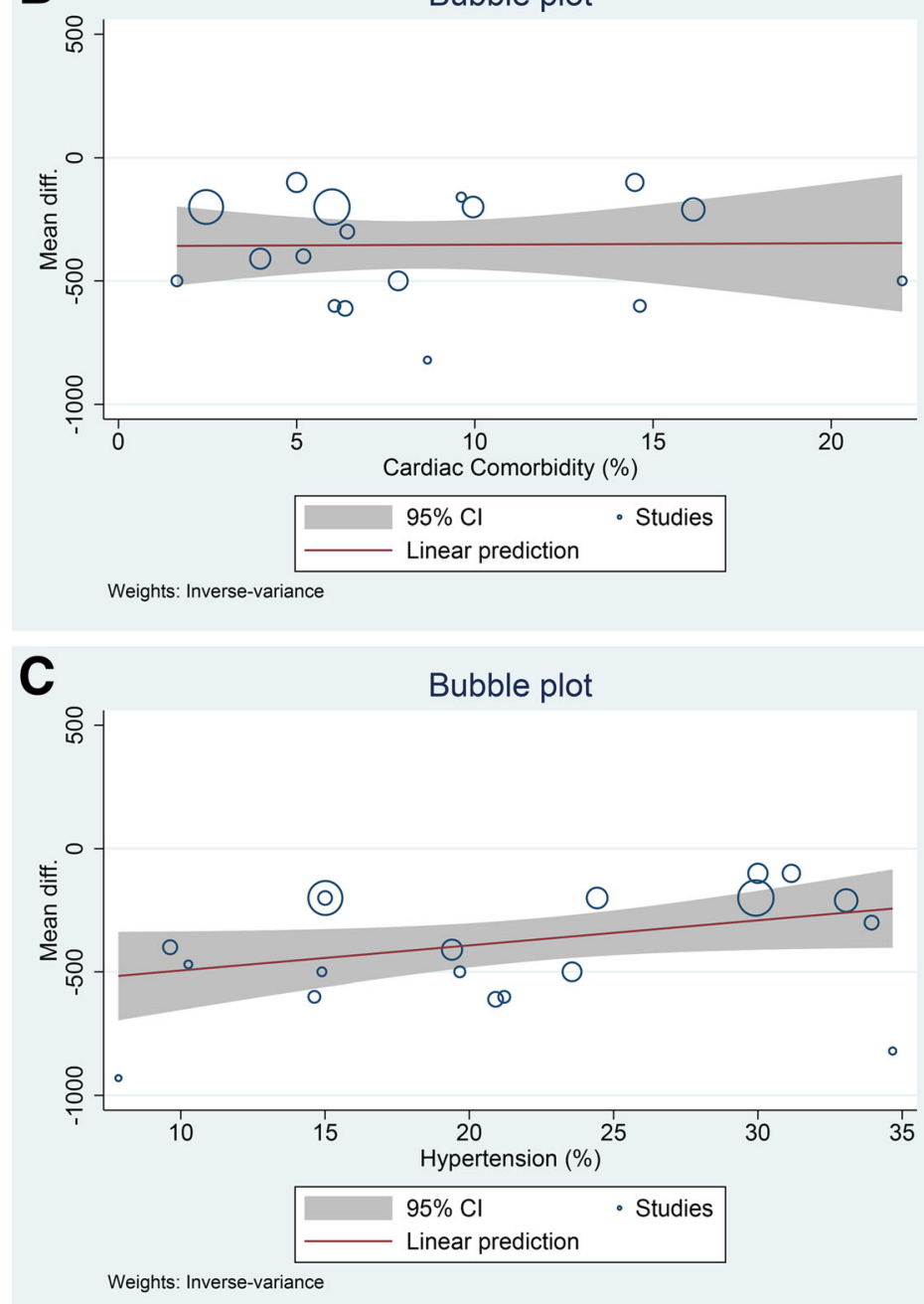

Fig. 3 Lymphopenia and severe COVID-19. Lymphopenia was associated with severe COVID 
hypertension and diabetes did not significantly affect the lymphocyte count difference between poor and good outcome.

Our understanding of the pathogenesis of lymphocyte reduction in COVID-19 might possibly be enlightened by studies of other similar beta-CoV infection, including severe acute respiratory syndrome (SARS)-CoV and Middle East respiratory syndrome (MERS)-CoV [34]. Peripheral $\mathrm{T}$ lymphocytes, both $\mathrm{CD} 4+$ and $\mathrm{CD} 8+$, are rapidly reduced in acute SARS-CoV infection hypothetically due to lymphocyte sequestration in specific target organs [35]. Although MERS-CoV and SARS-CoV are structurally similar, they bind to different receptors to facilitate entry. SARS-CoV attaches to angiotensinconverting enzyme 2 (ACE2) to enter the host cells, while MERS-CoV attaches to a different receptor, namely dipeptidyl peptidase 4 (DPP4) [36]. Although the mechanism of significant lymphocyte reduction in severe COVID-19 remains unclear, there are hypothesis other than lymphocyte infiltration and sequestration in the lungs, gastrointestinal tracts, and or lymphoid tissues: (1) lymphocytes express the ACE2 receptor and may be a direct target of SARS-CoV-2 infection [37], and (2) an increase of pro-inflammatory cytokines in COVID-19, especially IL-6, could induce further lymphocyte reduction [34].

\section{Implication for clinical practice}

Lymphopenia can be used as a marker for poor prognosis in COVID-19 and in younger patients in particular.

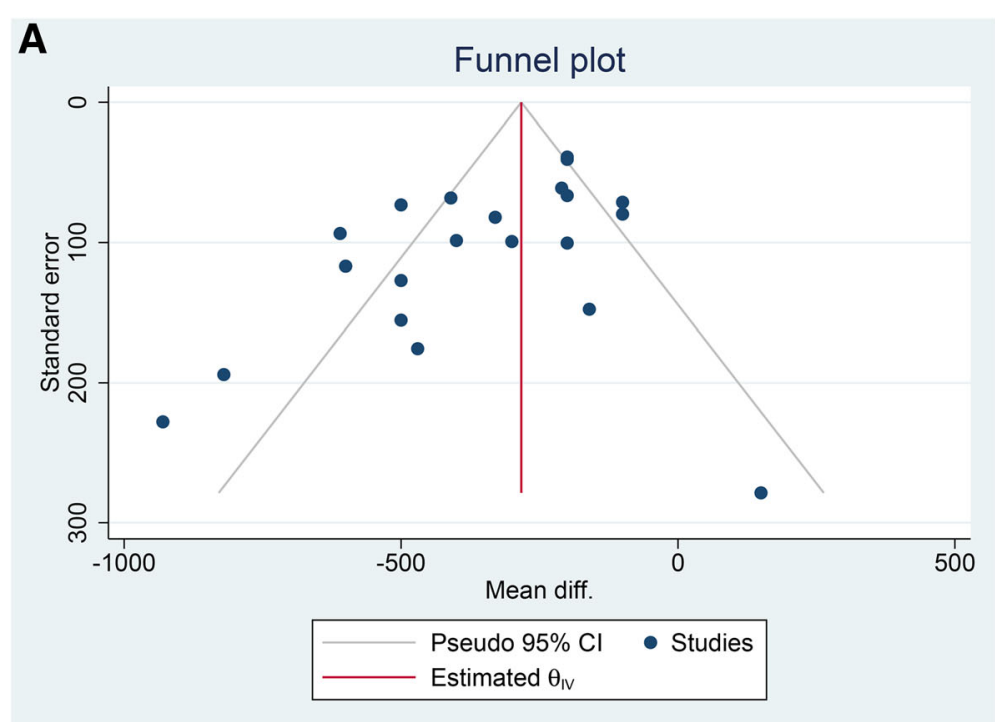

B

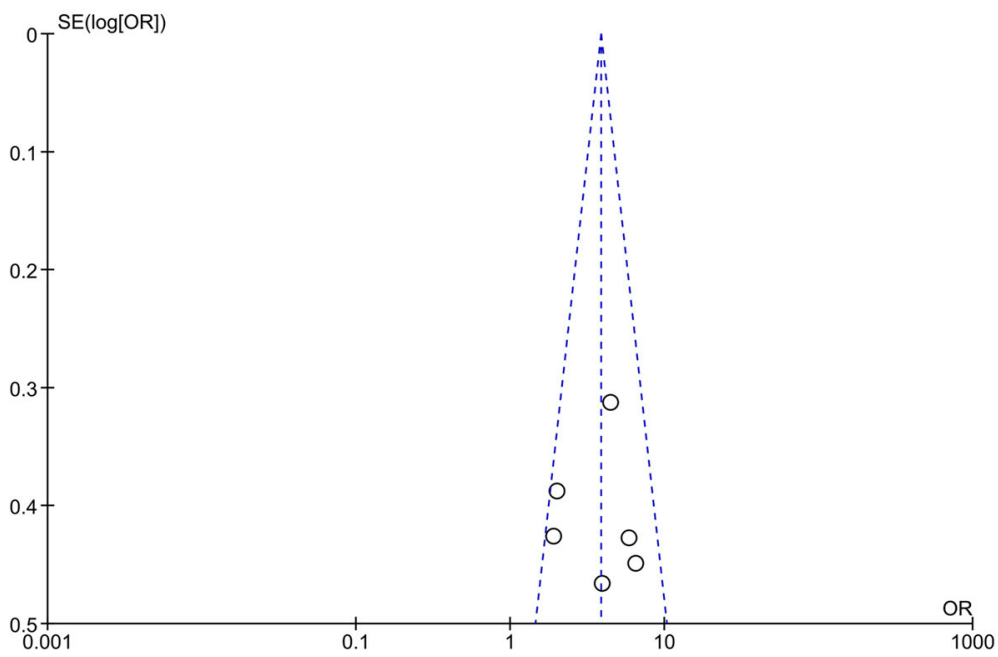

Fig. 4 Publication bias. Funnel plot analysis showed asymmetrical shape for composite poor outcome and lymphocyte count (a), but symmetrical shape for lymphopenia and composite poor outcome (b) 
Lymphopenia defined as lymphocyte count $\leq 1100$ cells $/ \mu \mathrm{L}$ is associated with threefold risk of poor outcome.

\section{Limitation}

The limitation of this systematic review and metaanalysis is the presence of publication bias. This is apparent in the lymphocyte count and composite poor outcome. Most of the articles included in the study were published at preprint server of which are not yet peerreviewed. Data curation from preprint server is crucial due to the novel and emergent nature of COVID-19; most of the studies are not yet published in journals. Most of the studies were exclusively from China; thus the possibility of the same patients reported more than once is high and may represent inaccurate scientific records. The included studies were also mostly retrospective in design. We encourage further studies to create prognostic model that include lymphopenia.

\section{Conclusion}

This meta-analysis showed that lymphopenia on admission was associated with poor outcome in patients with COVID-19.

\section{Supplementary information}

Supplementary information accompanies this paper at https://doi.org/10 1186/s40560-020-00453-4.

Additional file 1: Table S1. Electronic search strategy.

Additional file 2: Figure S1. Subgroup analysis performed for lymphopenia.

\section{Abbreviations \\ ACE: Angiotensin-converting enzyme; ACE2: Angiotensin-converting enzyme 2; ARB: Angiotensin receptor blocker; ARDS: Acute respiratory distress syndrome; COVID-19: Coronavirus disease 2019; DPP4: Dipeptidyl peptidase 4; ICU: Intensive care unit; MERS-CoV: Middle East respiratory syndrome coronavirus; MOF: Multi-organ failure; MD: Mean difference; OR: Odds ratio; SARI: Severe acute respiratory infection; SARS-Cov: Severe acute respiratory syndrome coronavirus; SD: Standard deviation; WHO: World Health Organization}

\section{Acknowledgements}

None

\section{Authors' contributions}

$\mathrm{IH}$ and RP developed the concept and drafted the manuscript. $\mathrm{H}$ and RP performed data acquisition, data analysis, and statistical analysis and approved the final version.

\section{Funding}

None

\section{Availability of data and materials}

All data generated or analyzed during this study are included in this published article. Corresponding author (R.P) can be contacted for more information.

Ethics approval and consent to participate Not applicable
Consent for publication

Not applicable

\section{Competing interests}

The authors declare that they have no competing interests

\section{Author details}

${ }^{1}$ Faculty of Medicine, Universitas Pelita Harapan, Tangerang, Banten, Indonesia. ${ }^{2}$ Department of Internal Medicine, Hasan Sadikin General Hospital-Faculty of Medicine, Universitas Padjadjaran, Bandung, Indonesia.

Received: 3 April 2020 Accepted: 4 May 2020

Published online: 24 May 2020

\section{References}

1. World Health Organization. Coronavirus disease (COVID-19) outbreak [Internet]. 2020. Available from: https://www.who.int/westernpacific/ emergencies/covid-19.

2. World Health Organization. Coronavirus disease 2019 (COVID-19) Situation Report - 79. World Heal. Organ. 2020

3. Chen N, Zhou M, Dong X, Qu J, Gong F, Han Y, et al. Epidemiological and clinical characteristics of 99 cases of 2019 novel coronavirus pneumonia in Wuhan, China: a descriptive study. Lancet Elsevier Ltd. 2020:395:507-13.

4. Pranata R, Huang I, Lukito A. Raharjo SB. Elevated N-terminal Pro-Brain Natriuretic Peptide is Associated with Increased Mortality in Patients with COVID-19 - Systematic Review and Meta-analysis. Postgrad Med J. 2020 [Early View].

5. Huang C, Wang Y, Li X, Ren L, Zhao J, Hu Y, et al. Clinical features of patients infected with 2019 novel coronavirus in Wuhan. China Lancet. 2020:395:497-506

6. Yang $X, Y u$ Y, Xu J, Shu H, Xia J, Liu H, et al. Clinical course and outcomes of critically ill patients with SARS-CoV-2 pneumonia in Wuhan, China: a singlecentered, retrospective, observational study. Lancet Respir Med Elsevier Ltd. 2020;2600:1-7.

7. Ruan Q, Yang K, Wang W, Jiang L, Song J. Clinical predictors of mortality due to COVID-19 based on an analysis of data of 150 patients from Wuhan, China. Intensive Care Med. Springer Berlin Heidelberg; 2020;.

8. World Health Organization. Clinical management of severe acute respiratory infection (SARI) when COVID-19 disease is suspected. 2020;1-21. Available from: https://www.who.int/publications-detail/clinical-management-ofsevere-acute-respiratory-infection-when-novel-coronavirus-(ncov)-infectionis-suspected.

9. World Health Organization. Report of the WHO-China Joint Mission on Coronavirus Disease 2019 (COVID-19) [Internet]. Available from: https:// www.who.int/publications-detail/report-of-the-who-china-joint-mission-oncoronavirus-disease-2019-(covid-19).

10. Zhang G, Hu C, Luo L, Fang F, Chen Y, Li J, et al. Clinical features and outcomes of 221 patients with COVID-19 in Wuhan, China. medRxiv. 2020; 2020.03.02.20030452

11. Zhang J Jin, Dong X, Cao Y Yuan, Yuan Y Dong, Yang Y Bin, Yan Y Qin, et al. Clinical characteristics of 140 patients infected with SARS-CoV-2 in Wuhan, China. Allergy Eur J Allergy Clin Immunol. 2020;1-12.

12. Wan S, Xiang $Y$, Fang W, Zheng $Y$, Li B, Hu Y, et al. Clinical features and treatment of COVID-19 patients in Northeast Chongqing. J Med Virol. 2020; $0-1$.

13. Qu R, Ling $Y$, Zhang $Y-H$, Wei L-Y, Chen $X$, Li X, et al. Platelet-to-lymphocyte ratio is associated with prognosis in patients with corona virus disease-19. J Med Virol. 2020:0-3.

14. Qin C, Zhou L, Hu Z, Zhang S, Yang S, Tao Y, et al. Dysregulation of immune response in patients with COVID-19 in Wuhan. China Clin Infect Dis. 2020;53:1689-99.

15. Wang Y, Zhou Y, Yang Z, Xia D, Geng S. Clinical characteristics of patients with severe pneumonia caused by the 2019 novel coronavirus in Wuhan, China. medRxiv. 2020;1-15

16. Feng Z, Yu Q, Yao S, Luo L, Duan J, Yan Z, et al. Early prediction of disease progression in 2019 novel coronavirus pneumonia patients outside Wuhan with CT and clinical characteristics. medRxiv. 2020;2020.02.19.20025296.

17. Lei L, Jian-ya G, Hu W, Zhang X, Gua L, Liu C, et al. Clinical characteristics of 51 patients discharged from hospital with COVID-19 in Chongqing, China. medRxiv. 2020;2020.02.20.20025536. 
18. Liu J, Li S, Liu J, Liang B, Wang X, Wang H, et al. Longitudinal characteristics of lymphocyte responses and cytokine profiles in the peripheral blood of SARS-CoV-2 infected patients. medRxiv. 2020;2020.02.16.20023671.

19. Cai Q, Huang D, Ou P, Yu H, Zhu Z, Xia Z, et al. COVID-19 in a designated infectious diseases hospital outside Hubei Province, China. medRxiv. 2020; 2020.02.17.20024018.

20. Zhou F, Yu T, Du R, Fan G, Liu Y, Liu Z, et al. Clinical course and risk factors for mortality of adult inpatients with COVID-19 in Wuhan, China: a retrospective cohort study. Lancet [Internet]. Elsevier Ltd. 2020;6736:1-9 Available from: https://doi.org/10.1016/S0140-6736(20)30566-3.

21. Liu J, Liu Y, Xiang P, Pu L, Xiong H, Li C, et al. Neutrophil-to-lymphocyte ratio predicts severe illness patients with 2019 novel coronavirus in the early stage. medRxiv. 2020;.

22. Tabata S, Imai K, Kawano S, Ikeda M, Kodama T, Miyoshi K, et al. Non-severe vs severe symptomatic COVID-19: 104 cases from the outbreak on the cruise ship "Diamond Princess" in Japan. medRxiv. 2020;.

23. Chen M, Fan Y, Wu X, Zhang L, Guo T, Deng K, et al. Clinical characteristics and risk factors for fatal outcome in patients with 2019-coronavirus infected disease (COVID-19) in Wuhan, China. SSRN Electron J. 2020;

24. Wang D, Hu B, Hu C, Zhu F, Liu X, Zhang J, et al. Clinical characteristics of 138 hospitalized patients with 2019 novel coronavirus-infected pneumonia in Wuhan, China. JAMA - J Am Med Assoc. 2020;1-9.

25. Cao M, Zhang D, Wang Y, Lu Y, Zhu X, Li Y, et al. Clinical features of patients infected with the 2019 novel coronavirus (COVID-19) in Shanghai, China. medRxiv. 2020;2020.03.04.20030395

26. Wu C, Chen X, Cai Y, Xia J, Zhou X, Xu S, et al. Risk factors associated with acute respiratory distress syndrome and death in patients with coronavirus disease 2019 pneumonia in Wuhan, China. JAMA Intern Med. 2020;1-10

27. Yanli L, Wenwu S, Jia L, Liangkai C, Yujun W, Lijuan Z, et al. Clinical features and progression of acute respiratory distress syndrome in coronavirus disease 2019. medRxiv. 2020;1-9.

28. Guan W-J, Ni Z-Y, Hu Y, Liang W-H, Ou C-Q, He J-X, et al. Clinical characteristics of coronavirus disease 2019 in China. N Engl J Med. 2020:113.

29. Liu W, Tao Z-W, Lei W, Ming-Li Y, Kui L, Ling Z, et al. Analysis of factors associated with disease outcomes in hospitalized patients with 2019 novel coronavirus disease. Chin Med J. 2020;0:1

30. Lin Y, Kim J, Metter EJ, Nguyen H, Truong T, Lustig A, et al. Changes in blood lymphocyte numbers with age in vivo and their association with the levels of cytokines/cytokine receptors. Immun Ageing Immunity \& Ageing. 2016:13:1-10.

31. Kuster GM, Pfister O, Burkard T, Zhou Q, Twerenbold R, Haaf P, et al. SARSCoV2: should inhibitors of the renin-angiotensin system be withdrawn in patients with COVID-19? Eur Heart J [Internet]. 2020; Available from: https:// academic.oup.com/eurhearti/advance-article/doi/10.1093/eurheartj/ ehaa235/5810479.

32. Huang I, Lim MA, Pranata R. Diabetes mellitus is associated with increased mortality and severity of disease in COVID-19 pneumonia - a systematic review, meta-analysis, and meta-regression. Diabetes Metab Syndr Clin Res Rev [Internet]. 2020; Available from: https://linkinghub.elsevier.com/retrieve/ pii/S1871402120300837.

33. Pranata R, Lim MA, Huang I, Raharjo SB, Lukito AA. Hypertension is Associated with Increased Mortality and Severity of Disease in COVID-19 Pneumonia - A Systematic Review, Meta-analysis, and Meta-regression. J Renin Angiotensin Aldosterone Syst. 2020. [Early View].

34. Lin L, Lu L, Cao W, Li T. Hypothesis for potential pathogenesis of SARS-CoV2 infection--a review of immune changes in patients with viral pneumonia. Emerg Microbes Infect Taylor \& Francis. 2020;0:1-14.

35. Li T, Qiu Z, Zhang L, Han Y, He W, Liu Z, et al. Significant changes of peripheral T lymphocyte subsets in patients with severe acute respiratory syndrome. J Infect Dis. 2004;189:648-51.

36. Raj VS, Mou H, Smits SL, Dekkers DHW, Müller MA, Dijkman R, et al. Dipeptidyl peptidase 4 is a functional receptor for the emerging human coronavirus-EMC. Nature. 2013;495:251-4.

37. Xu H, Zhong L, Deng J, Peng J, Dan H, Zeng X, et al. High expression of ACE2 receptor of 2019-nCoV on the epithelial cells of oral mucosa. Int J Oral Sci Springer US. 2020;12:1-5.

\section{Publisher's Note}

Springer Nature remains neutral with regard to jurisdictional claims in published maps and institutional affiliations.

\section{Ready to submit your research? Choose BMC and benefit from}

- fast, convenient online submission

- thorough peer review by experienced researchers in your field

- rapid publication on acceptance

- support for research data, including large and complex data types

- gold Open Access which fosters wider collaboration and increased citations

- maximum visibility for your research: over $100 \mathrm{M}$ website views per year

At $\mathrm{BMC}$, research is always in progress.

Learn more biomedcentral.com/submissions 